\title{
Radiological Toolbox User's Manual
}

\section{December 31, 2003}

Prepared by

K. F. Eckerman

A. L. Sjoreen 


\title{
DOCUMENT AVAILABILITY
}

Reports produced after January 1, 1996, are generally available free via the U.S. Department of Energy (DOE) Information Bridge.

Web site http://www.osti.gov/bridge

Reports produced before January 1, 1996, may be purchased by members of the public from the following source.

\author{
National Technical Information Service \\ 5285 Port Royal Road \\ Springfield, VA 22161 \\ Telephone 703-605-6000 (1-800-553-6847) \\ TDD 703-487-4639 \\ Fax 703-605-6900 \\ E-mail info@ntis.fedworld.gov \\ Web site http://www.ntis.gov/support/ordernowabout.htm
}

Reports are available to DOE employees, DOE contractors, Energy Technology Data Exchange (ETDE) representatives, and International Nuclear Information System (INIS) representatives from the following source.

Office of Scientific and Technical Information

P.O. Box 62

Oak Ridge, TN 37831

Telephone 865-576-8401

Fax 865-576-5728

E-mail reports@adonis.osti.gov

Web site http://www.osti.gov/contact.html

This report was prepared as an account of work sponsored by an agency of the United States Government. Neither the United States government nor any agency thereof, nor any of their employees, makes any warranty, express or implied, or assumes any legal liability or responsibility for the accuracy, completeness, or usefulness of any information, apparatus, product, or process disclosed, or represents that its use would not infringe privately owned rights. Reference herein to any specific commercial product, process, or service by trade name, trademark, manufacturer, or otherwise, does not necessarily constitute or imply its endorsement, recommendation, or favoring by the United States Government or any agency thereof. The views and opinions of authors expressed herein do not necessarily state or reflect those of the United States Government or any agency thereof. 
ORNL/TM-2004/27

\section{Radiological Toolbox User’s Manual}

K. F. Eckerman

A. L. Sjoreen

Date Published: February 2004

Prepared for

United States Nuclear Regulatory Commission

by

OAK RIDGE NATIONAL LABORATORY

P.O. Box 2008

Oak Ridge, Tennessee 37831-6285

managed by

UT-Battelle, LLC

for the

U.S. DEPARTMENT OF ENERGY

under contract DE-AC05-00OR22725 



\section{CONTENTS}

Page

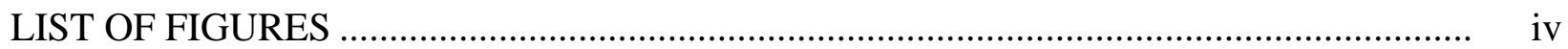

ABSTRACT ..........................................................................................................

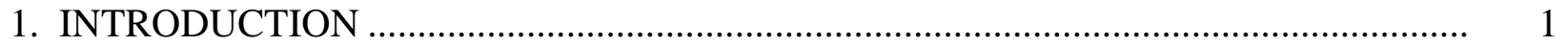

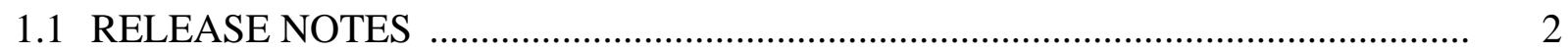

1.1.1 Installing the Software ....................................................................................... 2

1.1.2 Known Bugs in Version 1.0 ............................................................................. 3

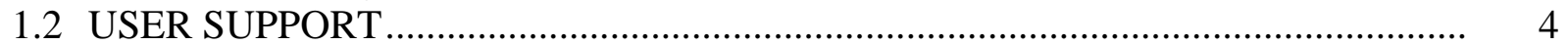

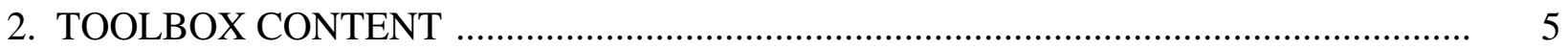

2.1 MENU ITEMS ....................................................................................... 5

2.2 ABSORBER DATA ………….................................................................. 5

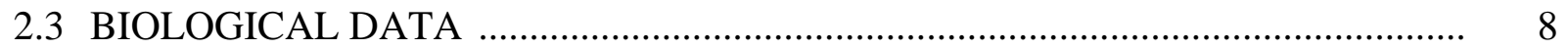

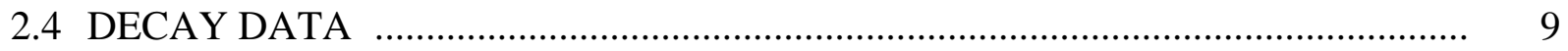

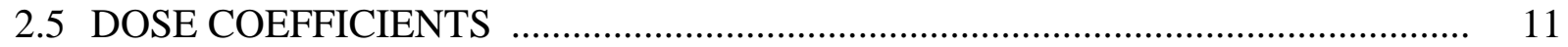

2.6 EARLY INHALATION ABSORBED DOSE COEFFICIENTS ................................ 12

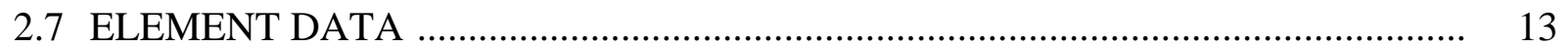

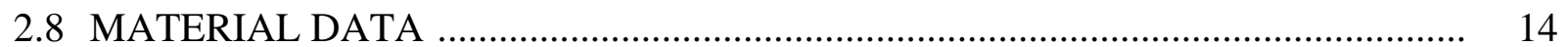

2.9 PUBLIC EXPOSURE DATA ……………………………………………….... 14

2.10 RADIATION FIELD DATA …………………………………………………... 16

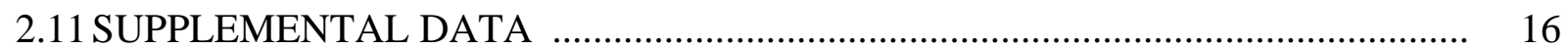

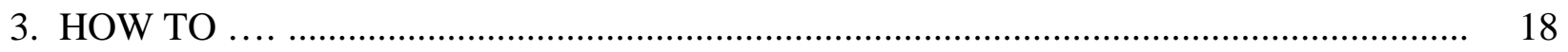

3.1 HOW TO USE THE DOSE COEFFICIENT NUCLIDE INPUT GRID .................... 18

3.2 HOW TO USE THE NUCLIDE, ELEMENT, MATERIAL CHOICE LISTS ............ 18

3.3 HOW TO EXPORT DATA ………………….................................................. 18

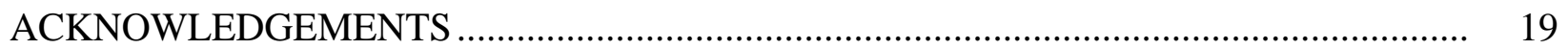

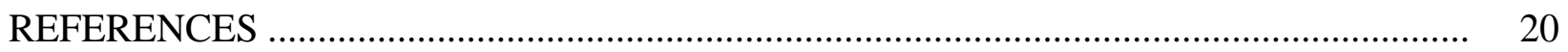




\section{LIST OF FIGURES}

Figure $\quad$ Page

1. Rad Toolbox initial screen ............................................................................... 3

2. The initial screen for the absorber data..................................................................

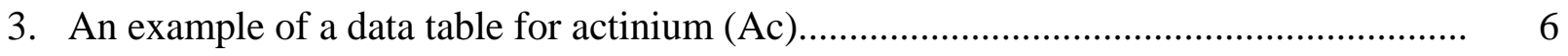

4. An example of a data plot for actinium (Ac) ................................................... 7

5. The initial screen for the biological data ........................................................ 9

6. The initial screen for the decay data ................................................................... 10

7. An example of a decay chain plot.................................................................... 11

8. The initial screen for the dose coefficient data ..................................................... 12

9. The initial screen for the absorbed dose coefficients for early effects ........................ 13

10. The initial screen for the element data............................................................... 14

11. The initial screen for the material data ............................................................... 15

12. The initial screen for the public exposure data .................................................... 15

13. The initial screen for the conversion coefficients for radiation fields ......................... 16

14. The initial screen for the supplemental data ...................................................... 17 


\begin{abstract}
A toolbox of radiological data has been assembled to provide users access to the physical, chemical, anatomical, physiological and mathematical data relevant to the radiation protection of workers and member of the public. The software runs on a PC and provides users, through a single graphical interface, quick access to contemporary data and the means to extract these data for further computations and analysis. The numerical data, for the most part, are stored within databases in SI units. However, the user can display and extract values using non-SI units. This is the first release of the toolbox which was developed for the U.S. Nuclear Regulatory Commission.
\end{abstract}





\section{INTRODUCTION}

The Radiological Toolbox (Rad Toolbox) was developed for the U.S. Nuclear Regulatory Commission (NRC). This computer application provides users access to a variety of physical, chemical, anatomical, physiological and mathematical data (and models) that are relevant to the protection of radiation workers and the public from radiation. The graphical interface enables viewing of the data and also provides a means to extract data for further computations and analysis. The numerical data, for the most part, are stored in SI units. However the user can display and extract the data using non-SI units. The data are stored in Microsoft Access databases and in flat ASCII files. This is the first release of the toolbox. The following data elements are included:

- Absorber data for elements and materials

o Alpha range and stopping power data

o Electron range and stopping power data

o Photon interaction cross-sections

o Neutron and photon kerma

- Biological data

o Biokinetic models

o Organ masses

o Dietary and respiratory intake rates

- $\quad$ Nuclear decay data - ICRP 38 (ICRP 1983) and JAERI (Endo 1999, 2001)

o Energy-intensity data

o Decay chains

- Dose coefficients (nuclide-specific)

o Radionuclide intake

- Radiation workers - ICRP Publications 30 and 68 (ICRP 1978, 1994)

- Members of the public - ICRP Publication 72 (ICRP 1996a)

o External irradiation - Federal Guidance Report 12 (EPA 1993)

- Submersion, immersion, ground plane, and soil

- Inhalation absorbed-dose coefficients for deterministic effects

o User-specified integration times

- Element data

o Elemental abundances

o Atomic masses

- Material data

o Elemental composition of common materials

- Public exposure data

o Natural background radiation doses

o Concentration data for naturally-occurring radioisotopes

- Dose coefficients for photon and neutron fields - ICRP Publication 74 (ICRP 1996b)

o Operational quantities

o Organ doses for six exposure geometries 
- Supplemental data

o Conversion factors

o SI units

o Formulas

o Web references

For the most part, the software simply accesses the databases and converts the requested values to the units specified by the users. However, computational modules are used to calculate the inhalation dose coefficients for deterministic effects for the time period specified by the user and to compute the interaction coefficients for materials based on their elemental composition. The latter interaction coefficients are simply a linear combination of the elemental data. However, in the case of photons one must interpolate the data at the energies associated with the K- and L-edges. The software's help files provide ready access to textual information. Help is currently available on a broad range of topics ranging from a general nature (General menu item) to the details of the models that describe the fate of elements which have been absorbed in the body.

\subsection{RELEASE NOTES}

This is the first general release of the toolbox. All bugs found during the beta testing period have been addressed and most of the enhancements suggested in the beta review process have been included. The toolbox has been installed on Windows 2000, XP, and 98 (second edition).

\subsubsection{Installing the Software}

The toolbox is installed by running the distributed setup module TB_SETUP. During installation the system may report messages for which the 'ignore' option is the appropriate response. The installation will place a menu item on Windows' Start|Programs menu. Clicking on that item will invoke the software to display the screen in Fig. 1. The column of buttons on the left provides access to different data within the 'folders' appearing on the right. The software can be removed from the computer by clicking on My Computer|Control Panel|Add/Remove Programs and selecting "remove this software." 


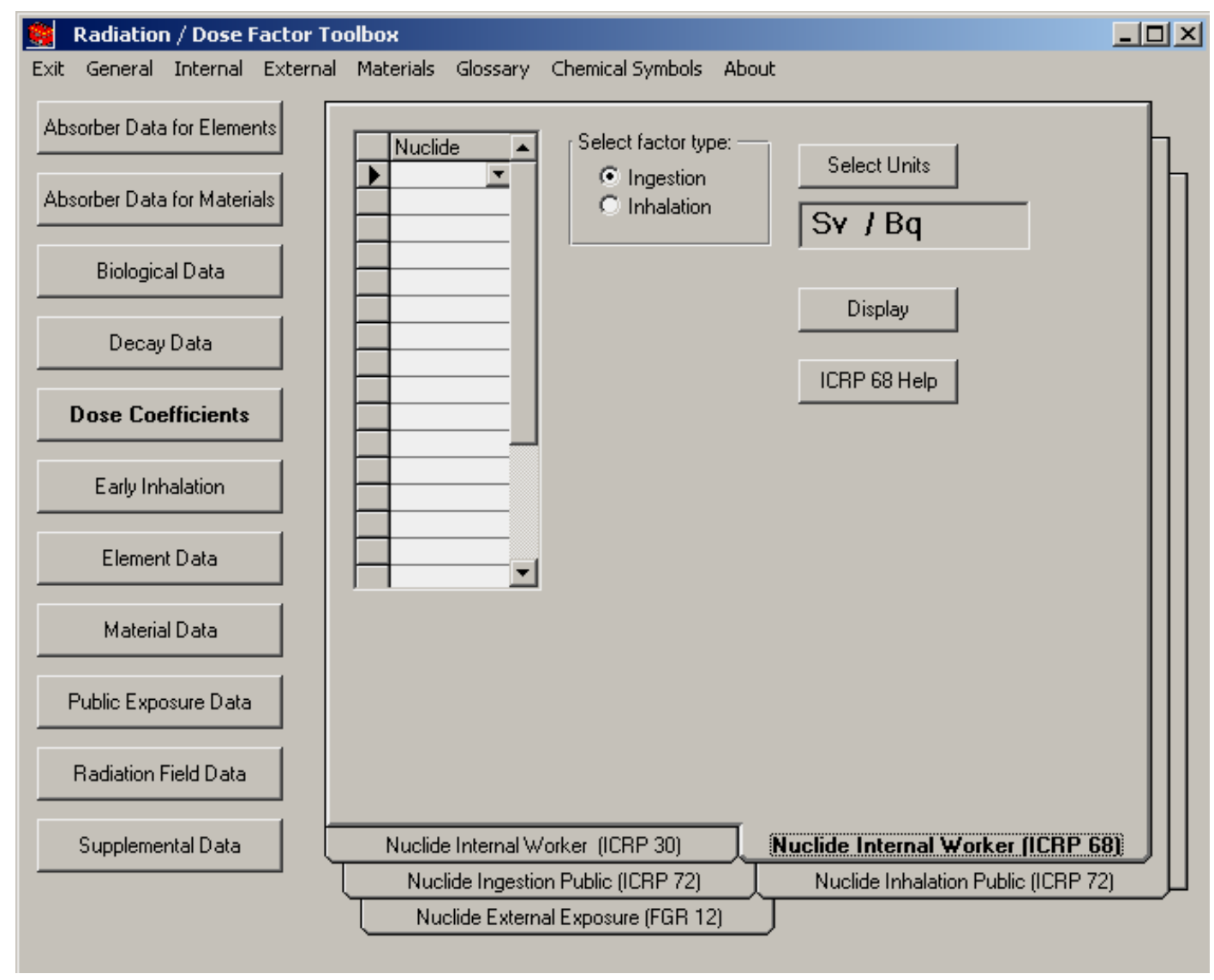

Fig. 1. Rad Toolbox initial screen.

\subsubsection{Known Bugs in Version 1.0}

There are two known “bugs” in this release:

a) In some instances, the graphical display of the decay chain associated with the parent radionuclide may contain artifacts; e.g., see the Am-242m chain. However, the software should not crash as the chain is assembled. Needless to say, the decay chain graphics have not been tested for all potential parent nuclides.

b) Within the Dose Coefficient folder the identity of a requested nuclide is retained as one goes from one type of coefficient to the next. If the requested nuclide does not exist in a subsequent coefficient type, then a message box appears stating "no nuclides found" - the correct response. However when $\mathbf{O K}$ is pressed an empty display screen appears - from which pressing OK again returns to the appropriate display. This "bug” can be demonstrated by pressing Dose Coefficients, selecting the "Public External Coefficient" folder and displaying the coefficients for Rn-222. After displaying the coefficients, pick any folder addressing radionuclide intake [e.g., Worker Coefficients (ICRP 30, 1978)]. Note that the requested nuclide is still Rn-222. However if one attempts to display the coefficients, the message box "Nuclide not found" appears. This occurs because dose coefficients for the intake of noble gas radionuclides are not addressed for internal irradiation (neither are radionuclides of half-life less than $10 \mathrm{~min}$ ) but they are for external irradiation. 


\subsection{SUPPORT}

If you encounter any problems running the Rad Toolbox, please contact Andrea Sjoreen (sjoreenal@ornl.gov or 865-574-5333) at Oak Ridge National Laboratory. If you have questions or comments of a technical nature, please contact Keith Eckerman (eckermankf@ornl.gov or 865-5746251) at Oak Ridge National Laboratory. Comments on style, usability, and other features that could be included would be appreciated. 


\section{TOOLBOX CONTENT}

When the toolbox is initiated, the screen of Fig. 1 appears. In the discussion below, the column of buttons on the left is said to refer to different sections of the toolbox while the structure on the right is referred to as a set of folders. Note these terms do not refer to the database structures, but are only used to facilitate the discussion. It may be helpful to consult Fig. 1 in the following sections. The section names correspond to the names of the buttons in that figure.

\subsection{HELP / MENU ITEMS}

The menu at the top of the screen allows access to the various help files in addition to other standard functions. The menu items are:

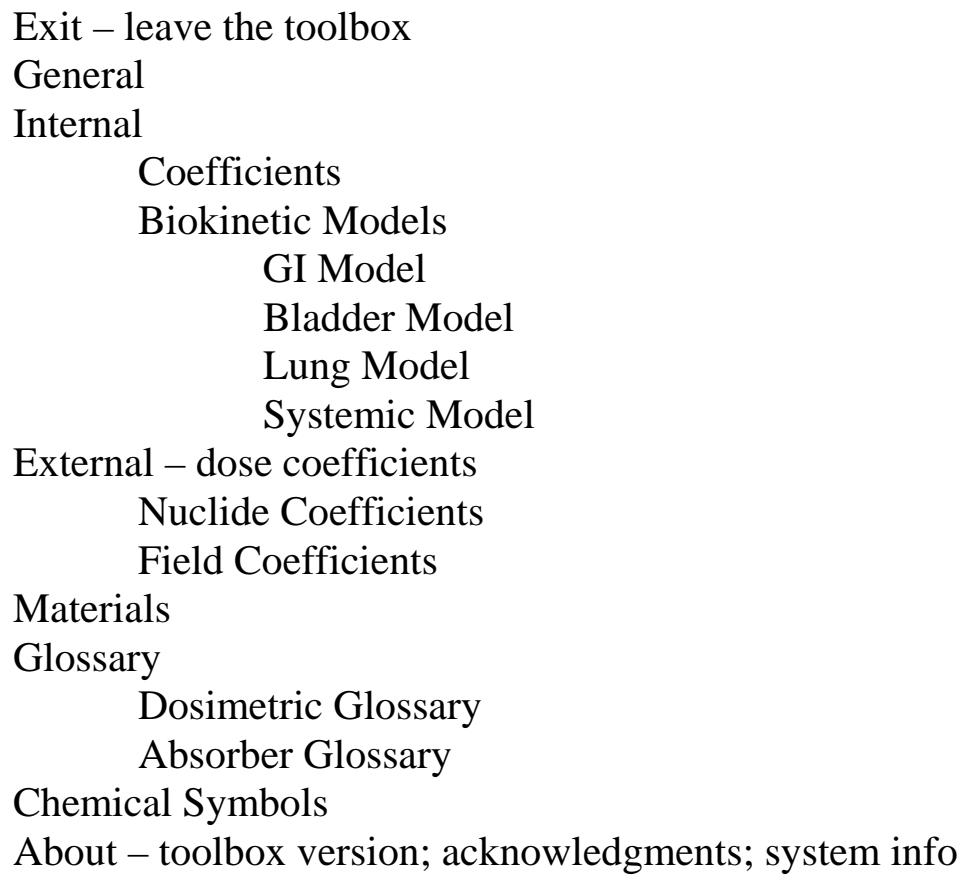

\subsection{ABSORBER DATA}

The Absorber Data section of the toolbox provides access to interaction coefficients for alpha, electron, photon and neutron radiations by element (Fig. 2) or material. The user may select the type of data (coefficient) for display and its units. Once the table (Fig 3.) is displayed the data may be plotted (Fig. 4), as a function of energy, by double-clicking on the data column of interest. The entire table may be exported to Microsoft Excel. Coefficients are not available for every element or for each radiation type. The kerma coefficients were taken from KERMAL, RSICC package DLC143 [Howerton (1986a and 1986b)]. All other data are from Hubbell and Seltzer (1997) (originally published as Hubbell and Seltzer 1995) and Berger et al. (1999) (originally published as Berger and Hubbell 1987a and 1987b). 


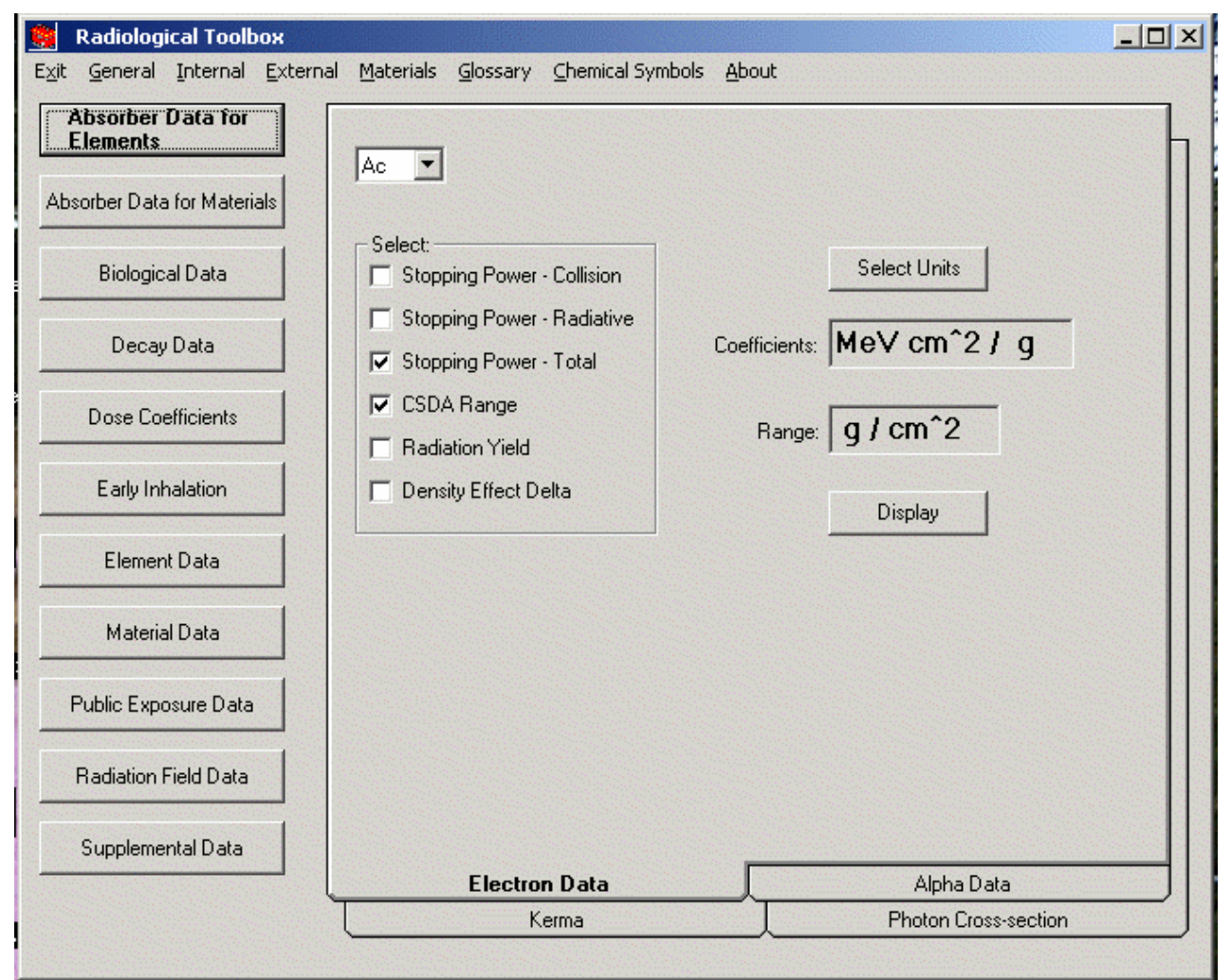

Fig. 2. The initial screen for the absorber data.

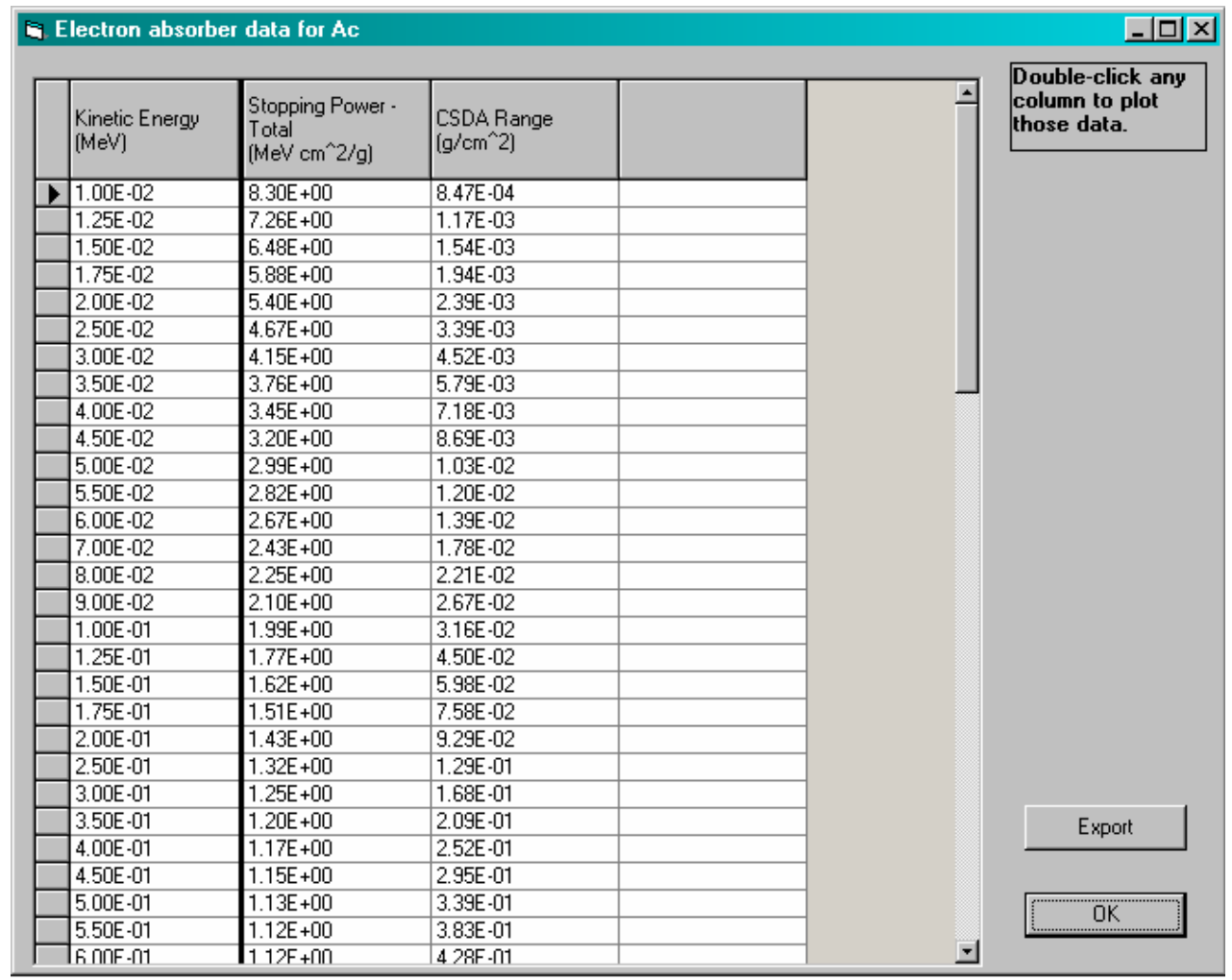

Fig. 3. An example of a data table for actinium (Ac). 


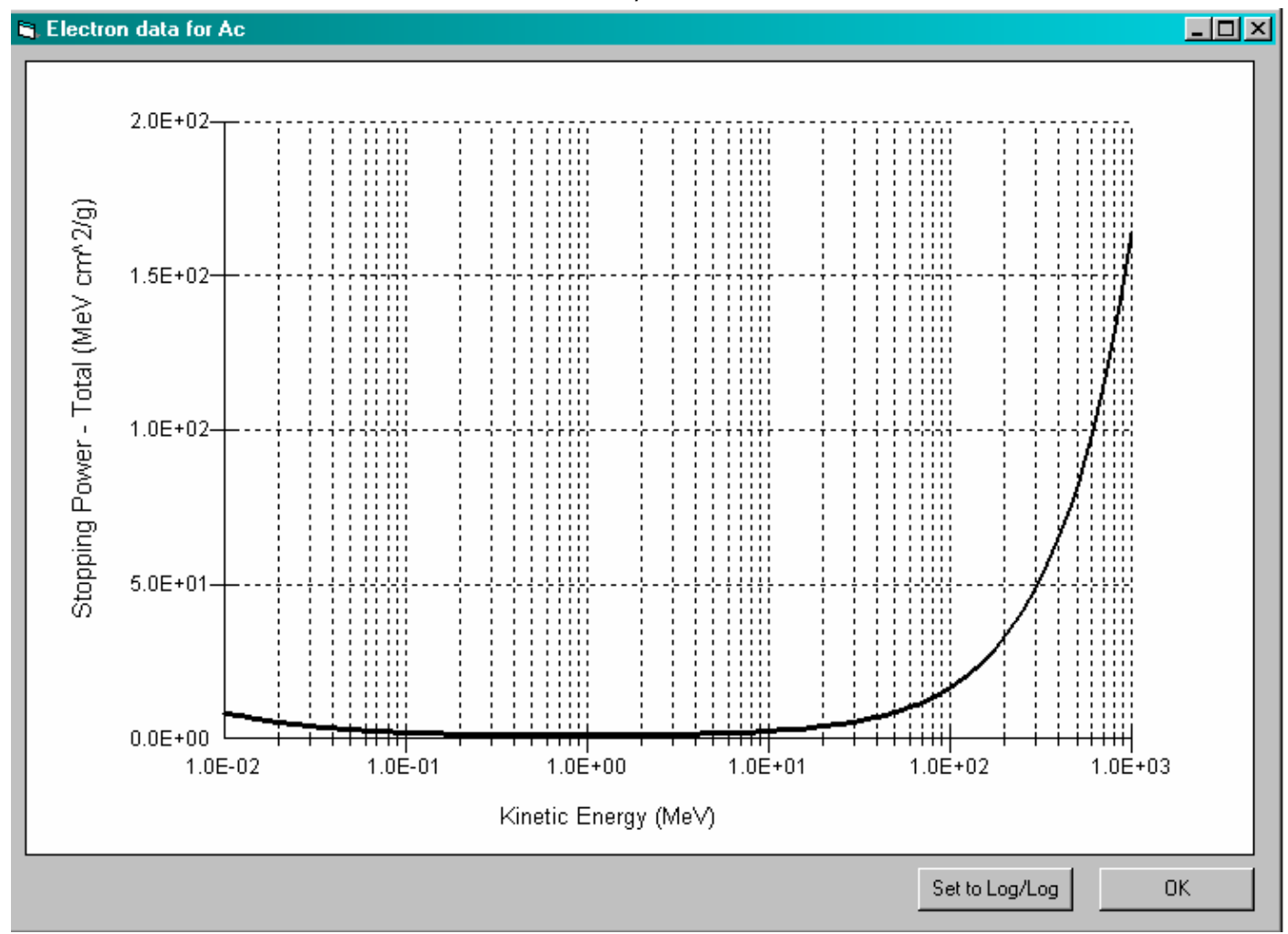

Fig. 4. An example of a data plot for actinium (Ac).

Photon cross section data are for the following processes:

scattering - coherent

scattering - incoherent

photoelectric absorption

pair production in a nuclear field

pair production in an electron field

total attenuation with coherent scattering

total attenuation without coherent scattering

mass energy-absorption coefficients

The electron interaction coefficients include:

stopping power - collision

stopping power - radiative

stopping power - total

continuous slowing dose approximation (CSDA) range

radiation yield

density effect delta

The alpha data available are:

electronic stopping power

nuclear stopping power

total stopping power

continuous slowing dose approximation (CSDA) range

Kerma coefficients are provided for:

photons

neutrons. 
8

The photon mass energy-absorption coefficients were tabulated at fewer photon energies than the other interaction coefficients. The values of the mass energy-absorption coefficients at the additional energies were obtained by log-log interpolation. The interpolated values appear with a colored background in the displayed tables.

Interaction and kerma coefficients for various materials were derived for the material of compositions specified in the Material Data section (Coursey et al. 2001) (originally published as Coplen 2001; Rosman and Taylor 1998; and Audi and Wapstra 1995). Thus, the material definitions in the Howerton references (1986a, 1986b) were not used. Since kerma data were only available for atomic numbers less than 30, only materials composed of these elements could be considered. In computing the coefficients for neutrons, the isotopes of the composition were assumed to be either the natural isotope or the most abundant isotope of the element.

\title{
2.3 BIOLOGICAL DATA
}

The Biological Data section (Fig. 5) of the toolbox contains data on the following:

\author{
biokinetic models \\ composition of tissues \\ organ masses \\ food intake rates \\ inhalation rates \\ threshold and lethal doses.
}

These data are displayed in tables, many of which can be exported to Excel. The biokinetic models are from ICRP Publication 68 (ICRP 1994) and Publication 72 (ICRP 1996a). The data on the composition of tissues can be sorted by atomic number or fraction. The organ masses are from ICRP Publication 72 (ICRP 1996a). The compositions of tissues are from Coursey et al. (2001). The inhalation rates are from ICRP Publication 68 (1994) and ICRP Publication 72 (1996a). The food intake rates are from Federal Guidance Report 13 (EPA 1999). The threshold and lethal doses are from Abrahamson et al. (1989). See also the EPA’s manual on PAGs (EPA 1992). 


\section{9}

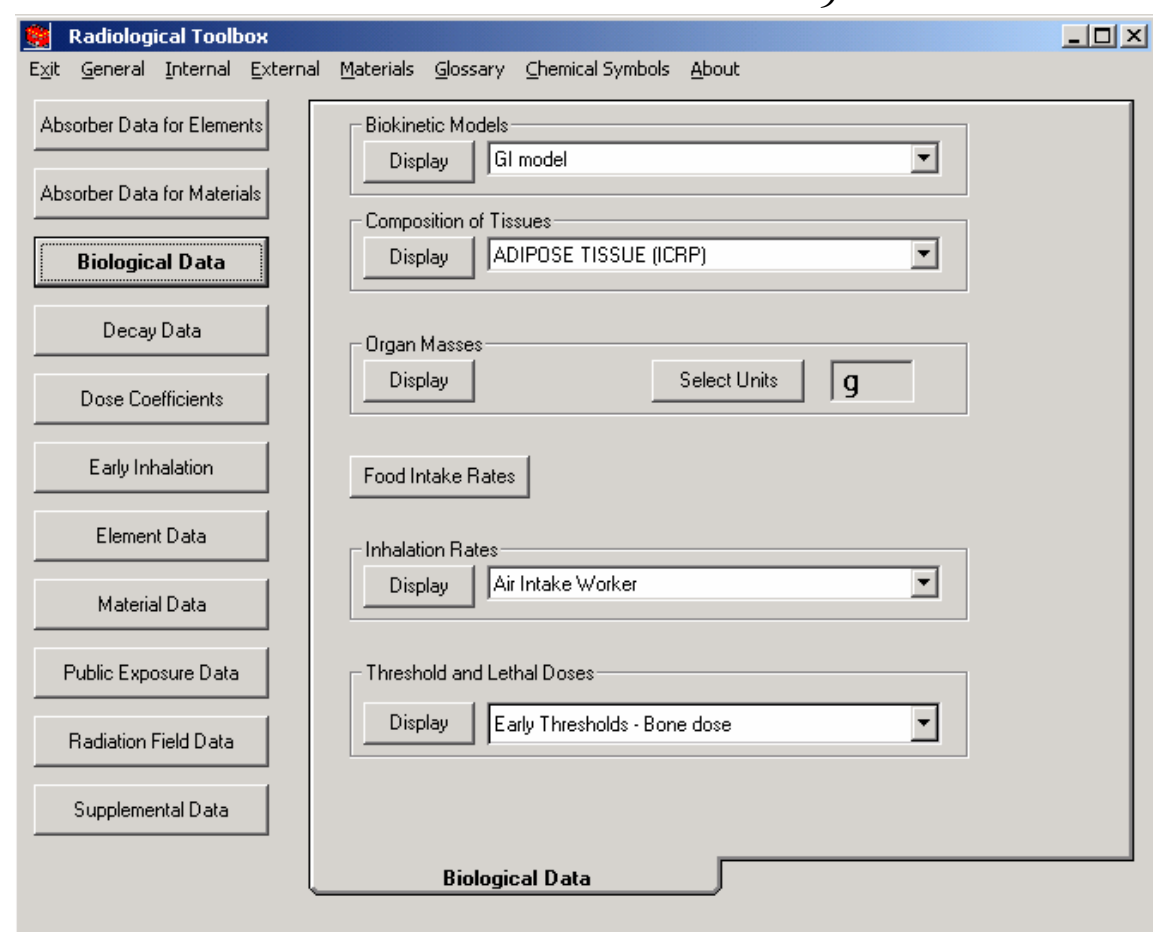

Fig. 5. The initial screen for the biological data.

\subsection{DECAY DATA}

The Decay Data section (Fig. 6) of the toolbox provides detailed data on the energy and intensities of the radiations emitted during nuclear transformations. Differential energy spectra are included for beta-emitting radionuclides and information on yield of radioactive decay products (daughters) in the decay chain. Two sets of data are included: the first from ICRP Publication 38 (ICRP 1983) and the second from a compilation by the Japan Atomic Energy Research Institute (JAERI) (Endo et al. 1999; Endo and Yamaguchi 2001). The data are in the format of the file structure of Eckerman et al. (1994). 


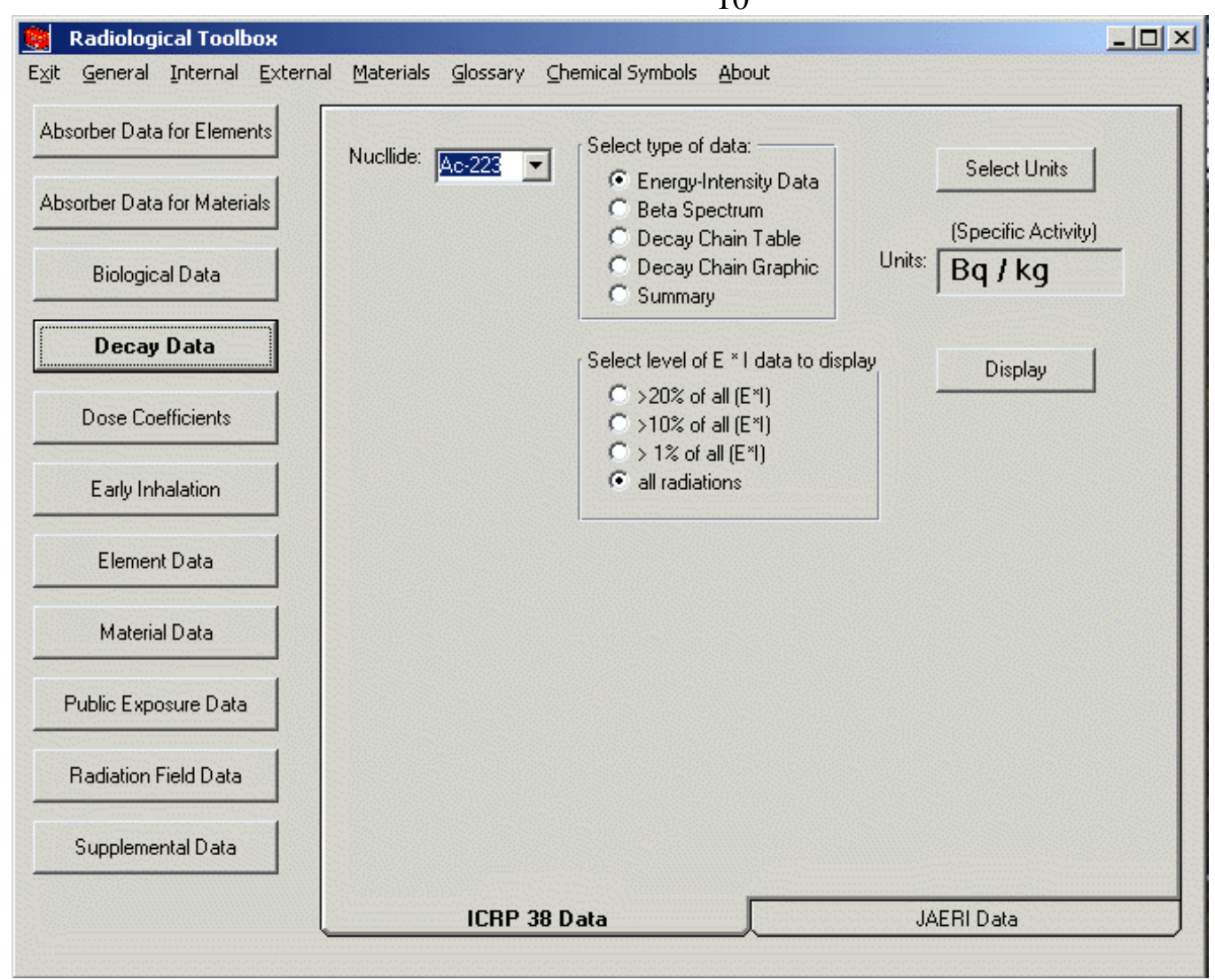

\section{Fig. 6. The initial screen for the decay data.}

Information on the energy and intensity of the emitted radiations are displayed in separate tables for alpha particles, beta transitions (average energy), photons, and mono-energetic electrons. The type of radiation is identified in each table and its associated code, the variable ICODE - as defined by Eckerman et al. (1994), is displayed. The beta table contains information on both $\beta_{+}+$and $\beta_{-}$ transitions; however the plotted spectrum is a composite over all beta transitions. $\mathrm{X}$ rays, gamma rays, and annihilation quanta are included in the photon table with their assigned ICODE. The data for internal conversion and Auger electrons are included in the monoenergetic electron table. The caption of each table lists the total number of that type of radiation emitted in the decay processes. In all tables the data are sorted by increasing energy. The tables include all the radiations without regard to the potential significance. It is possible to specify a fractional energy cutoff in percent, thus limiting the tables to those radiations that contribute more than the percent cutoff to the total emitted energy. For example, a cutoff of $1 \%$ would result in the table only containing radiations contributing more than $1 \%$ to the total energy for that radiation type. It is possible to sort the data by increasing intensity (yield) or by energy (the default sort variable). Each table may be separately exported to Excel. (When you press Export, only the radiations in the table being displayed are exported.)

The beta spectrum is displayed as a graph, but it is exported as a tabulation of the number of electrons $Y(E) d E$ emitted with energy between $E$ and $E+d E$ as a function of energy $E$. 
The decay chain table includes the specific activity, half-life, decay mode, and identification of radioactive daughters with their branching fractions. The default units for specific activity are $\mathrm{Bq} / \mathrm{kg}$. You may change these units. This table can not be exported.

The decay chain graphic includes half-lives and branching fractions (Fig. 7). The stable end product of the chain is included - it is not included in the decay chain table. The graphic can not be exported.

The decay data summary contains half life, decay mode, specific activity, total emitted energy, gamma constant, and a summary table of the four radiation types.

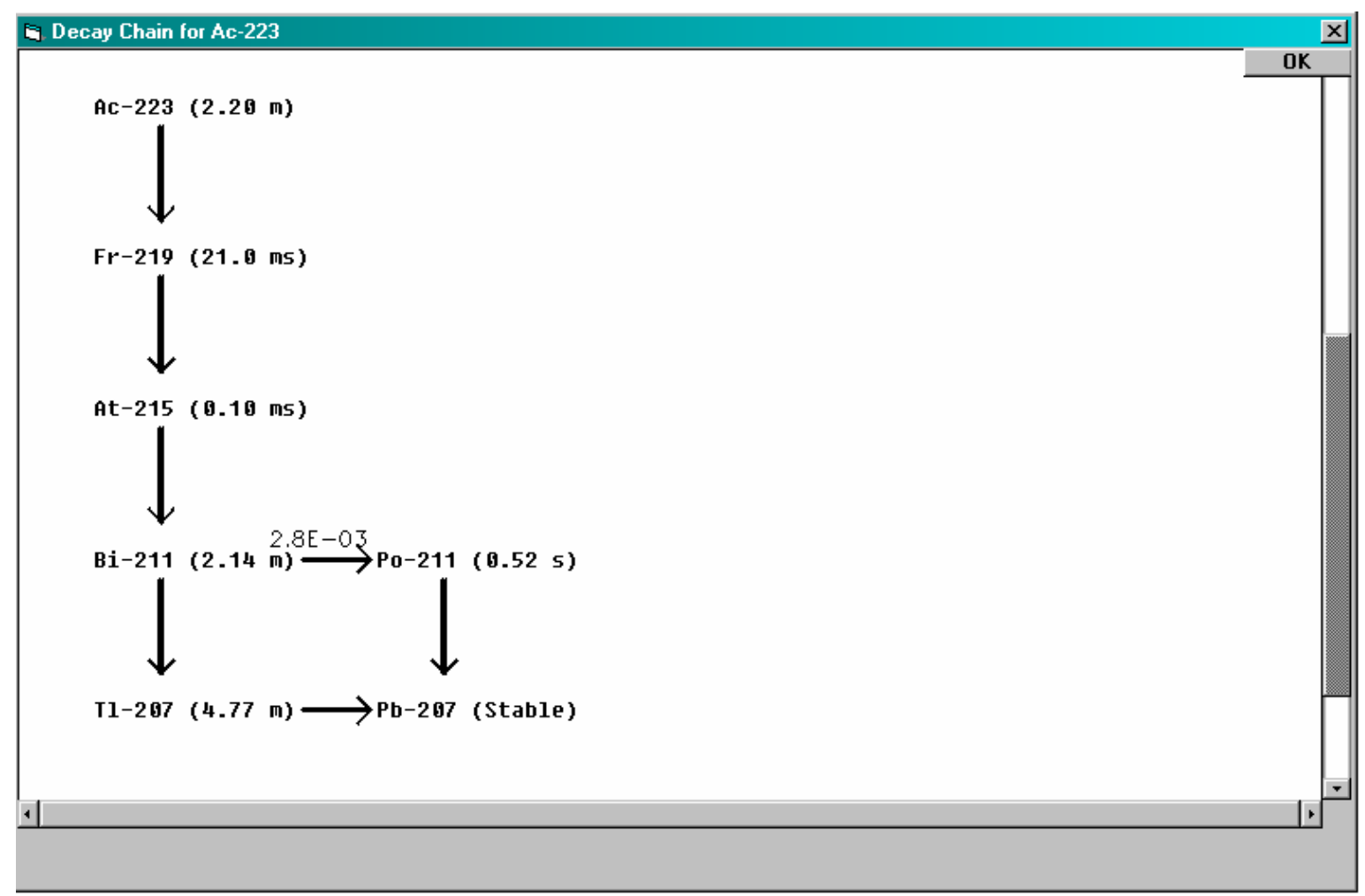

Fig. 7. An example of a decay chain plot.

\subsection{DOSE COEFFICIENTS}

The Dose Coefficients section (Fig. 8) of the toolbox provides access to five sets of nuclide-specific dose coefficients. They are: external dose rate coefficients for 826 radionuclides from Federal Guidance Report 12 (EPA 1993), the committed dose coefficients for the inhalation and ingestion of 738 radionuclides from ICRP Publications 30 and 68 (ICRP 1978; 1994), and age-dependent committed dose coefficients for the inhalation and ingestion intakes of 738 radionuclides by members of the public (six ages at intake) from ICRP 72 (ICRP 1996a). The coefficients were extracted, with permission, from the ICRP CD (ICRP 2001). From each set of coefficients it is possible to display up to 20 nuclides at a time for a chosen route of exposure or intake. The data in the display can be exported to an Excel spreadsheet. The default units used are SI; i.e., units of the original data. However, the user may specify non-SI units for display and export. 


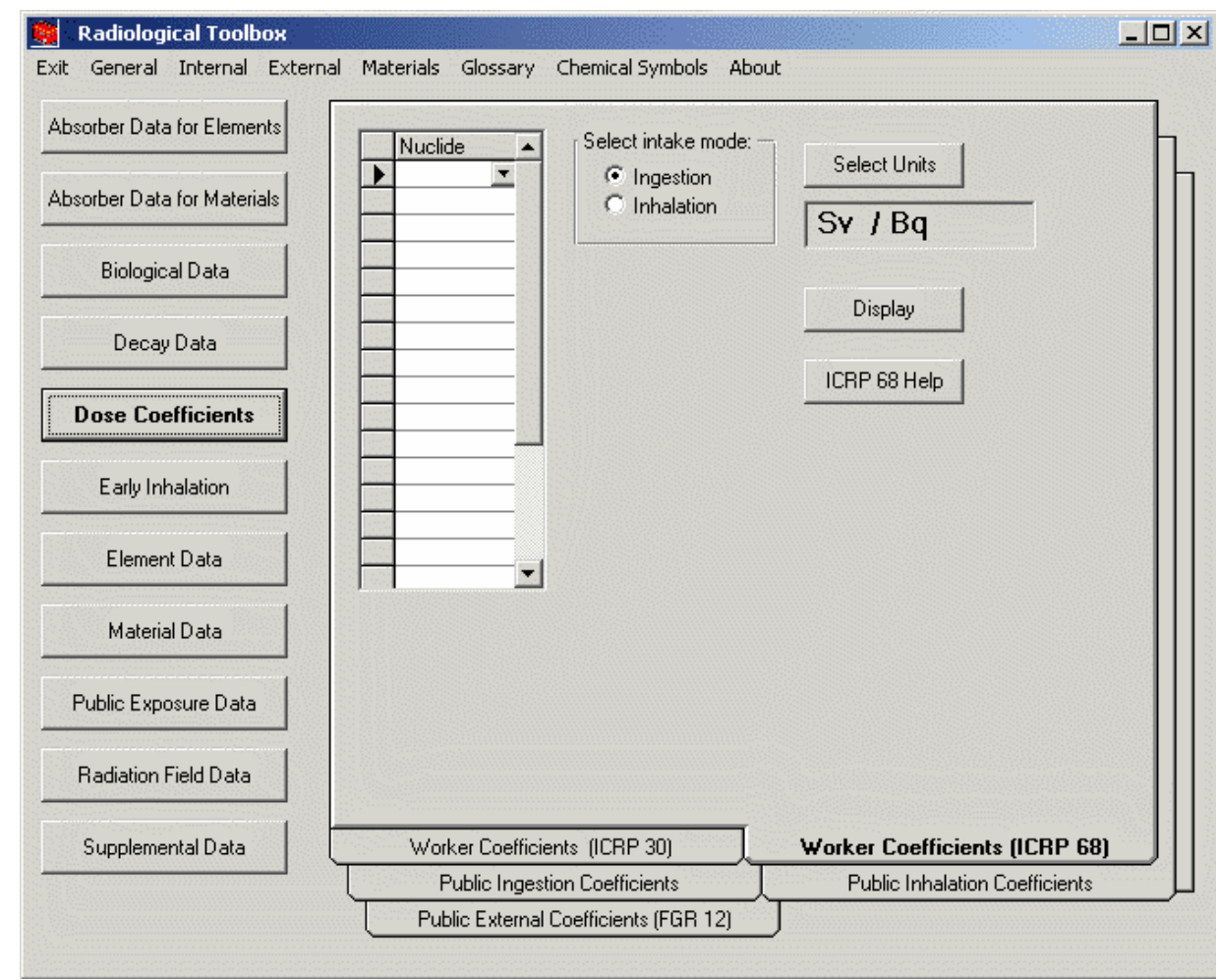

Fig. 8. The initial screen for the dose coefficient data.

Coefficients are displayed for the organ equivalent dose and the effective dose for each radionuclide selected. For exposure to radionuclide contamination outside the body, the coefficients are for the adult as considered in Federal Guidance Report 12 (EPA 1993). For the internal data, dose coefficients are displayed for all particulate absorption types (or clearance class in the ICRP 30 data set), for gases and vapors, if applicable, and the $f_{1}$ (fractional absorption from GI tract) is shown for the selected radionuclide. The type or class, $f_{1}$, and half-life are included in the display and in any table exported to Excel.

Note that both the set of nuclides selected for display and the selected units for the coefficients 'stick' across the dose coefficient data sets. That is, once a set of nuclides or units have been selected for dose coefficients, these units will be applied to all dose coefficients selected while running the toolbox, until different units are specified.

\subsection{EARLY INHALATION}

The Early Inhalation section (Fig. 9) of the toolbox provides access to the inhalation dose coefficients for early (deterministic) effects. These coefficients are presented in terms of absorbed dose - separate values are given for low and high LET. The organs available are small intestine, red marrow, lung (mass average), and alveolar interstitial region only. These coefficients are computed based on dosimetric data archived on the Federal Guidance Report 13 CD (EPA 2000). The user may specify integration times (up to 20 times) from 1 day to 10 years. The units of these coefficients may be changed. The coefficients may be exported to Excel. 


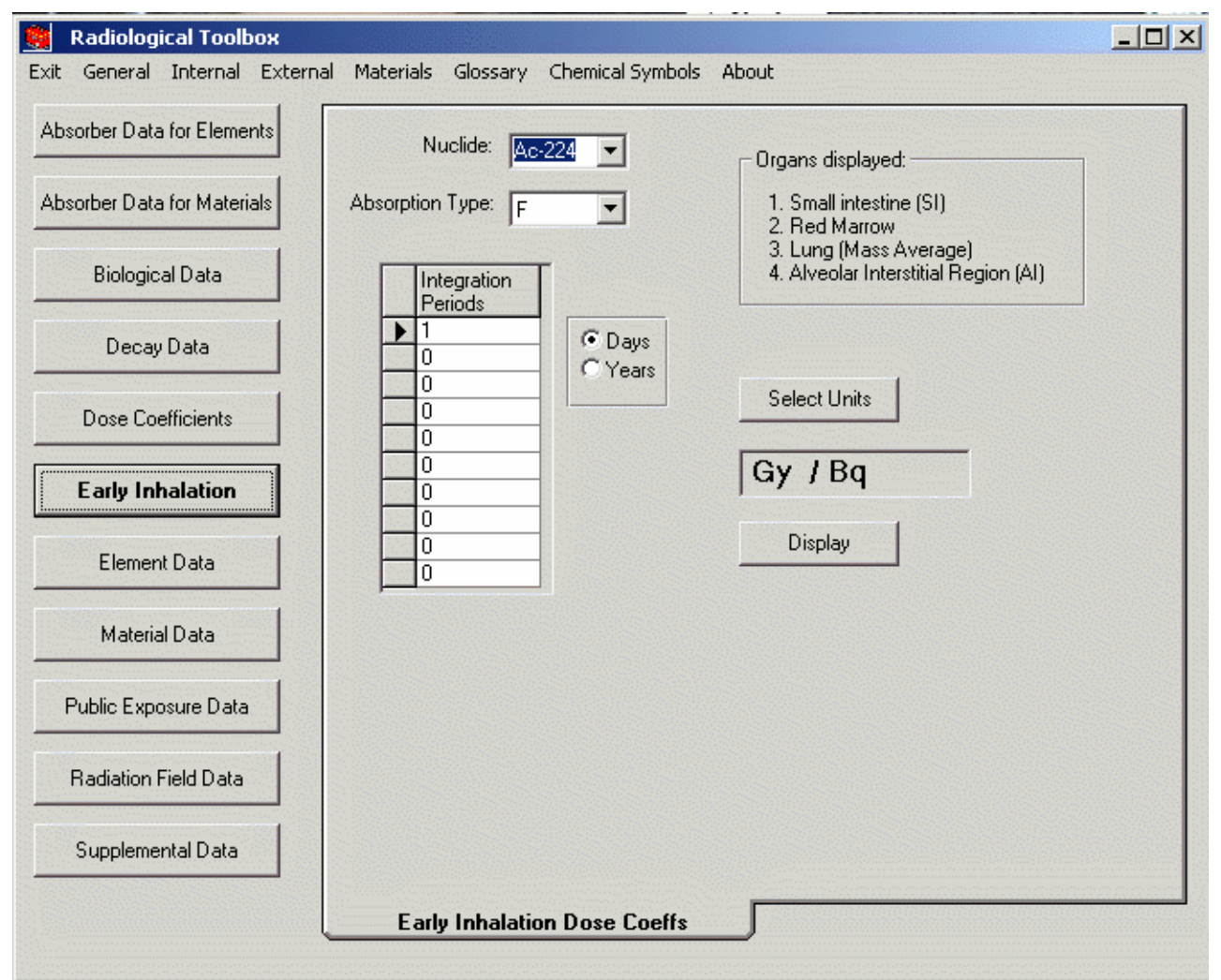

Fig. 9. The initial screen for the absorbed dose coefficients for early effects.

\subsection{ELEMENT DATA}

The Element Data section (Fig. 10) provides access to atomic mass and isotopic abundance data. These data may be exported to Excel spreadsheets. These data are from Coursey et al. (2001). Stable, primordial, and cosmogenic radioactive isotopes are marked with a colored background. These data were abstracted from the $16^{\text {th }}$ edition of the Chart of the Nuclides (Baum et al. 2002). 
14

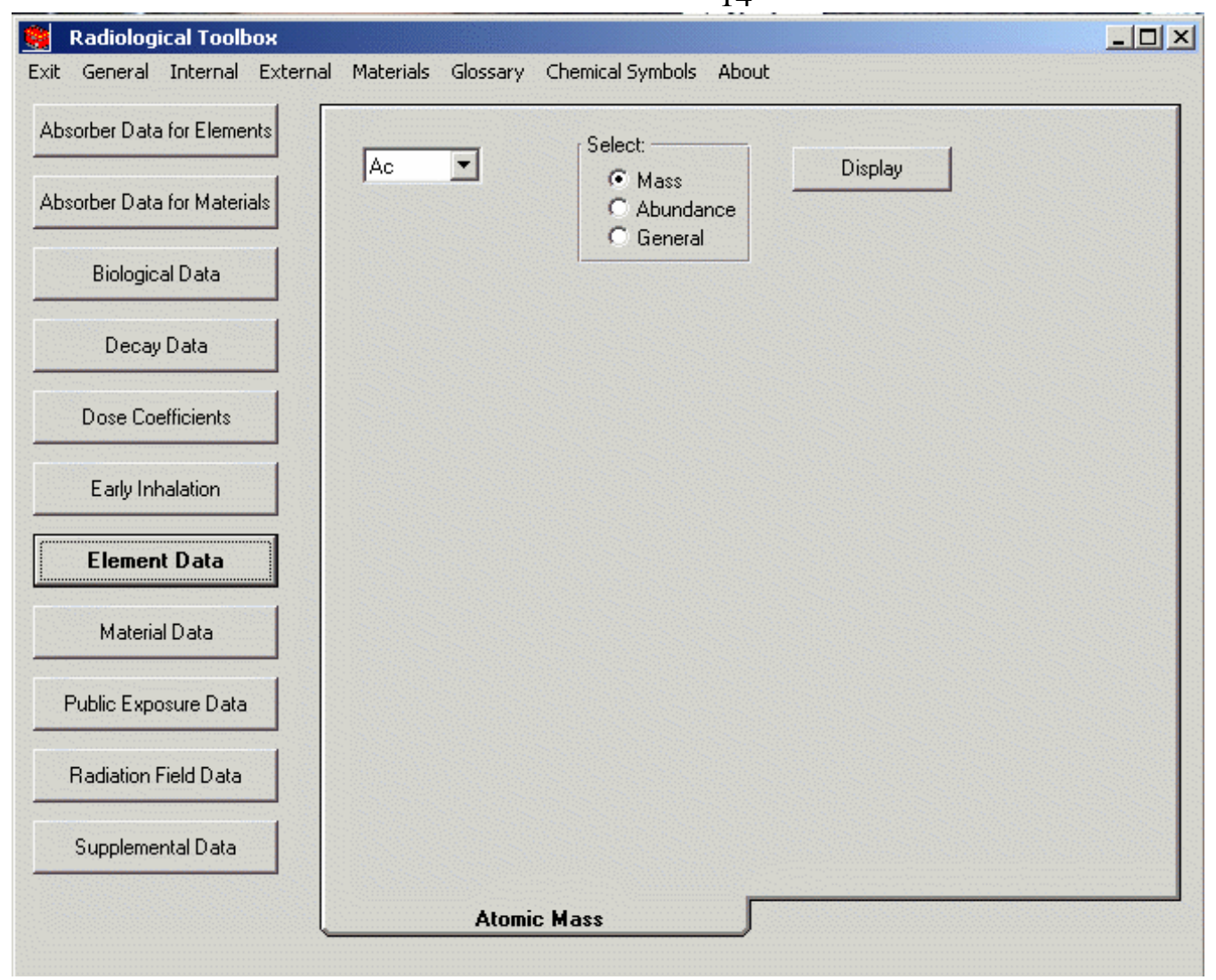

Fig. 10. The initial screen for the element data section.

\subsection{MATERIAL DATA}

The Material Data section (Fig. 11) provides access to composition data for selected materials. The composition data are displayed as atomic fraction. This table may be sorted by atomic number or fraction. These data may be exported to Excel spreadsheets. These data are from Coursey et al. (2001).

\subsection{PUBLIC EXPOSURE DATA}

The Public Exposure Data section (Fig. 12) contains data such as:

natural background radiation

background radiation in the body

concentrations of radionuclides in materials

concentrations of radionuclides in devices

concentrations of primordial radionuclides

typical exposures during medical procedures.

The natural background radiation and background radiation in the body data are from NCRP 94 (1988). The concentrations of radionuclides in materials are from Schneider et al. (2001). The 
concentrations of radionuclides in materials and of primordial radionuclides are from the Radiation Information Network (ISU 2003). The typical exposures during medical procedures are from RTM-96 (NRC 1996).

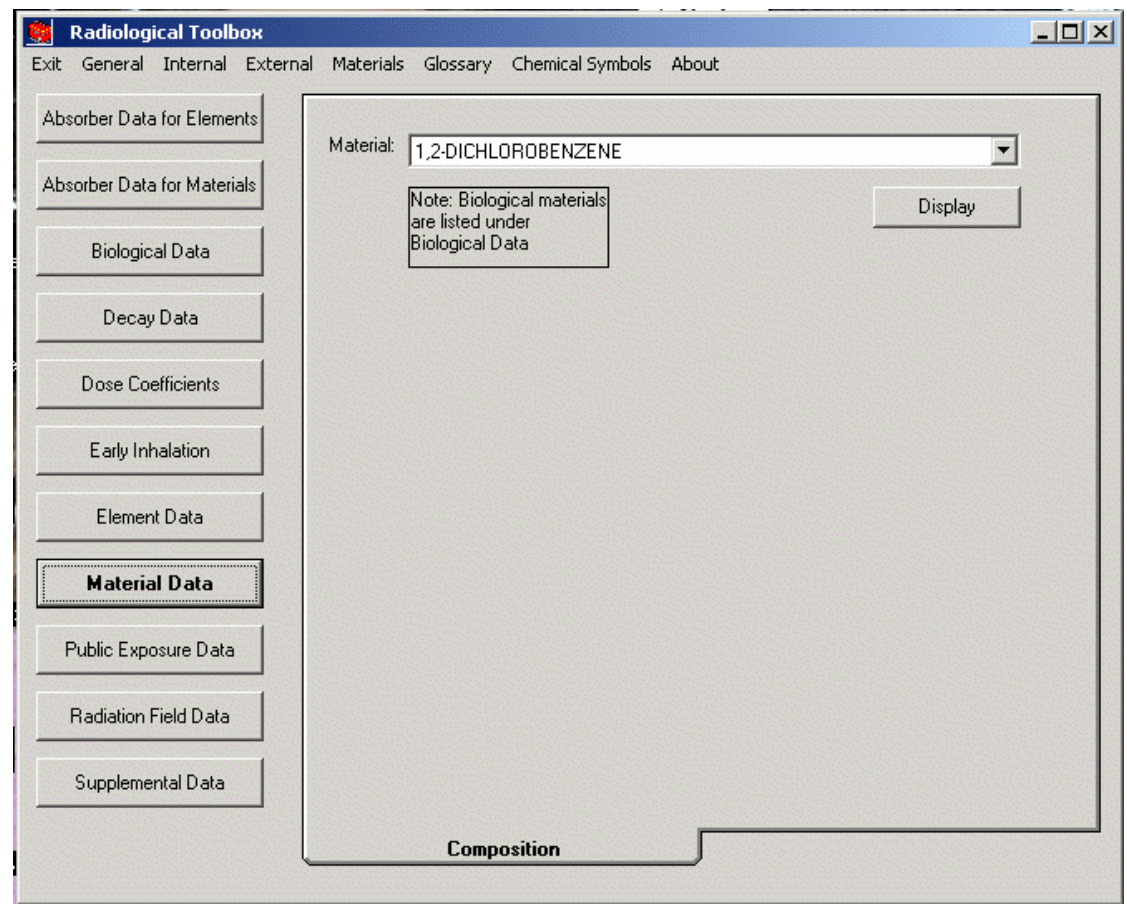

Fig 11. The initial screen for the material data.

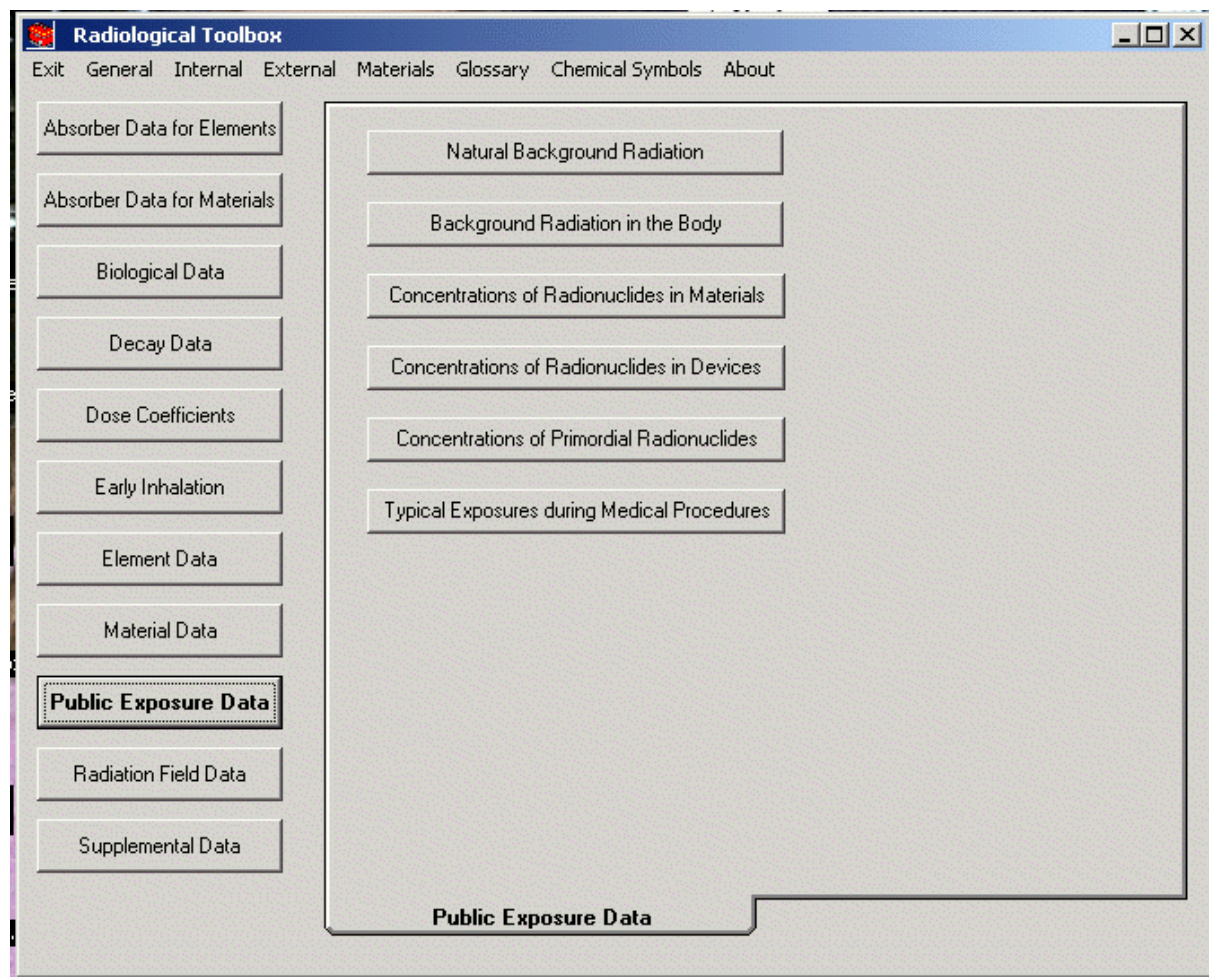

Fig 12. The initial screen for the public exposure data. 


\subsection{RADIATION FIELD DATA}

The Radiation Field Data section (Fig. 13) provides access to conversion coefficients for the operational quantities and organ dose coefficients for neutron and photon radiation fields. These data were compiled by a joint task group of the ICRP and the ICRU and were abstracted from ICRP Publication 74 (ICRP 1996b). Organ dose coefficients are available for six geometries: anteroposterier, postero-anterier, left-lateral, right-lateral, rotational and isotropic. Graphics of these geometries are displayed. Once the table is displayed, you may plot any column in the table by double-clicking on those data. The entire table may be exported to Excel.

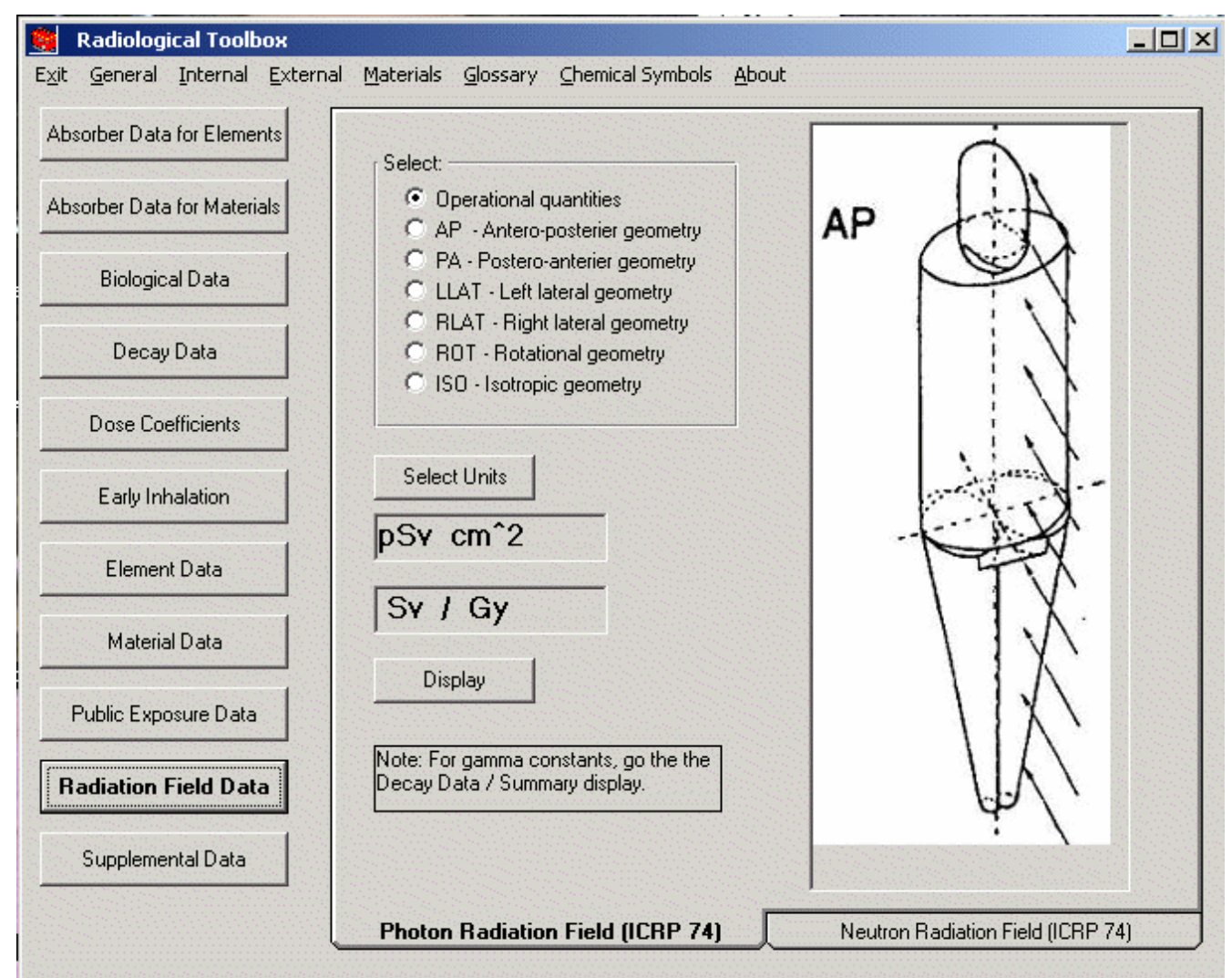

Fig. 13. The initial screen for the conversion coefficients for radiation fields.

\subsection{SUPPLEMENTAL DATA}

The Supplemental Data section (Fig. 14) provides access to other radiation and health-physics data. This section includes:

SI units

physical constants

conversion factors

equations

web links. 
The physical constants and conversion factors may be exported to the clipboard by rightclicking on the value. A simple web browser is available to view the web links. The SI units are from Baum et al. (2002). The physical constants and conversion factors are from Lide (1997). The equations are from various sources.

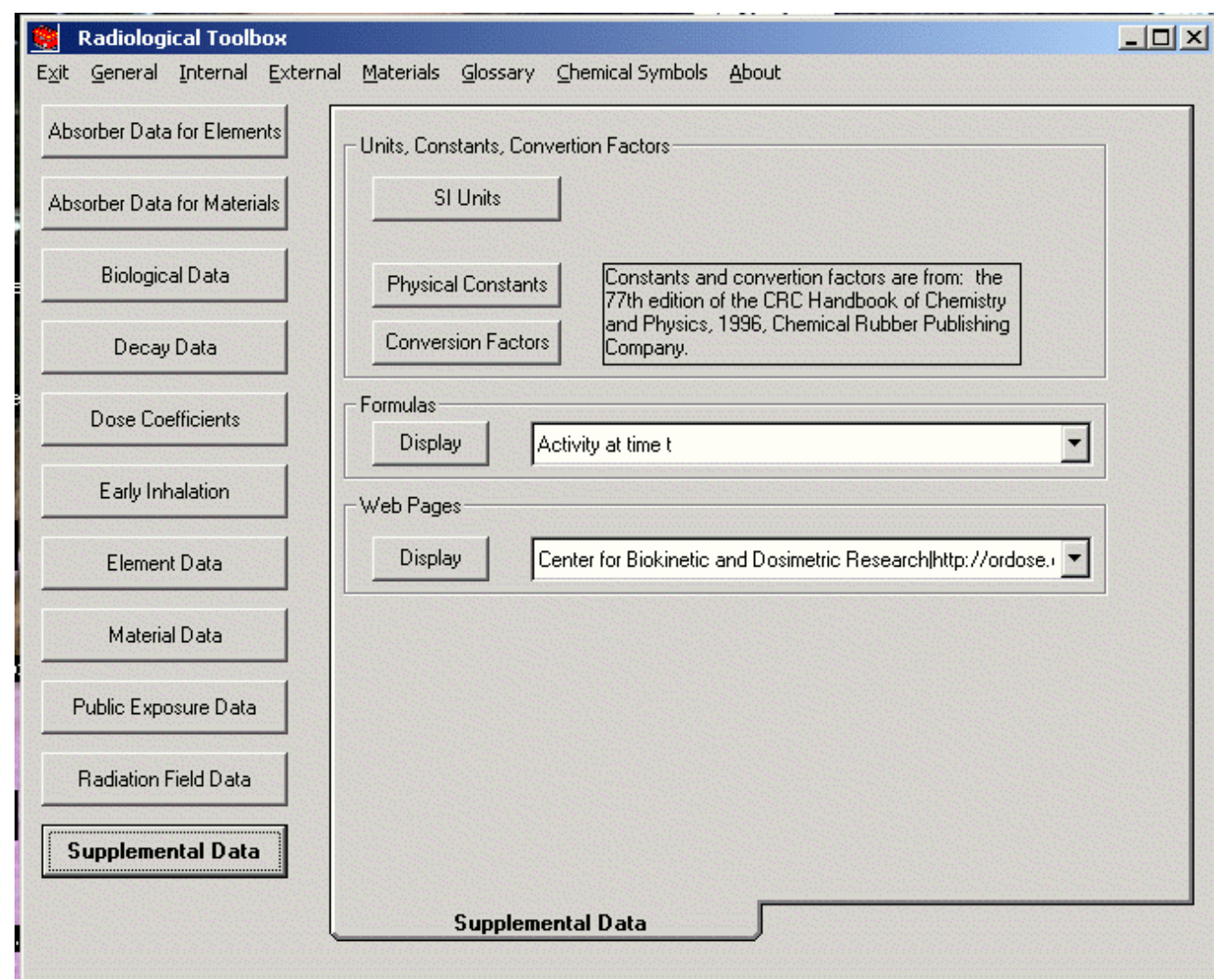

Fig. 14. The initial screen for the supplemental data. 


\subsection{HOW TO ...}

This section describes the use of some of the Rad Toolbox features.

\subsection{HOW TO USE THE DOSE COEFFICIENT NUCLIDE INPUT GRID}

Dose coefficients can be requested for up to 20 radionuclides in a single query. You may either type in the radionuclide name or select it from the choice list. Once the choice list is selected, you can navigate the list by typing the first few characters of the selected name. If you type in an invalid name (either from misspelling or from trying to access a radionuclide that is not included in that database), you will be shown an error message and you will not be able to leave that cell until you correct the mistake or blank the cell. You should always enter a name in the top cell of the list, but there may be blanks in between other entries. The table displayed will not necessarily have the radionuclides in the order that you entered the names.

\subsection{HOW TO USE THE NUCLIDE, ELEMENT, MATERIAL CHOICE LISTS}

For the choice lists where you select a single value, you may either type in the item name or select it from the choice list. Once the choice list is selected, you can navigate the list by typing the first few characters of the selected name. If you type in an invalid name (either from misspelling or from trying to access an item that is not included in that database), you will be shown an error message and you will not be able to leave the cell until you enter or select a valid name.

\subsection{HOW TO EXPORT DATA}

If you do not have Microsoft Excel on your PC, you cannot export data from the Rad Toolbox. An Export button is available on each table that may be exported. The first time that you press Export, a new Excel file is opened. The data in the table you are viewing are copied to the first sheet of that file. If you leave that Excel file open and export additional data, those data will be copied to the same sheet as the previously exported data. The new data will be positioned next to the previous data, with one blank column in between. If you close the Excel file, a new file will be opened when you next export. The Rad Toolbox will not export data to an existing file. 


\section{ACKNOWLEDGEMENTS}

The authors would like to acknowledge the following direct and indirect contributors to this work.

The International Commission on Radiological Protection for granting permission to extract the inhalation and ingestion dose coefficients from its CD (ICRP 2001) entitled "The ICRP Database of Dose Coefficients: Worker and Members of the Public.” This CD should be consulted for further details regarding dose coefficients. For example, the ICRP CD contains coefficients for aerosols of sizes other than the default sizes presented here.

The external dose coefficients, nuclear decay data, and dose coefficients for deterministic effects were assembled at ORNL under the sponsorship of the U.S. Environmental Protection Agency during the preparation of Federal Guidance Report 13.

The alpha, electron, and photon interaction coefficients were adapted from publications and codes of the National Institute of Science and Technology (NIST). In addition, the elemental composition of various materials was abstracted from these publications. These data underlie many reports of the International Commission on Radiation Units and Measurements (ICRU).

The nuclear decay data denoted as 'JAERI Data' were assembled from the publications and data files developed at the Japan Atomic Energy Research Institute. We gratefully acknowledge the assistance of A. Endo of JAERI.

Thanks to A. Phipps and T. Silk of the UK National Radiation Protection Board for their assistance in the preparation of some of the help files.

Special thanks to Harriett Karagiannis, the NRC Project Officer, and Sami Sherbini of NRC for their support throughout this project. Their guidance has been most helpful.

We very much appreciate the efforts of our Beta testers: Christopher B. Nelson, Luis Bertelli (LANL), Pat Scofield (ORNL), and Rick Rodriquez (ORNL). We also appreciate the reviewers of this document: Pat Scofield and Kathy Gant (ORNL). All remaining errors are the sole responsibility of the authors. 


\section{REFERENCES}

Audi, G. and A. H. Wapstra. 1995. “The 1995 Update to the Atomic Mass Evaluation.” Nucl. Phys. A. 595(4), 409.

Abrahamson, S., et al. 1989. Health Effects Models for Nuclear Power Plant Accident Consequences Analysis, Low LET Radiation, Part II: Scientific Bases for Health Effects Models. NUREG/CR4214, Rev. 1 (SAND85-7185), U.S. Nuclear Regulatory Commission, Washington, DC.

Baum, E. M., H. D. Knox, and T. R. Miller. 2002. "Nuclides and Isotopes, $16^{\text {th }}$ Edition of the Chart of the Nuclides.” Knolls Atomic Power Laboratory, Inc. Schenectady, NY, 2002, http://ChartOfTheNuclides.com.

Berger, M. J. and J. H. Hubbell. 1987a. Photon Cross Sections on a Personal Computer. NBSIR 873597; National Institute of Standards and Technology, Gaithersburg, MD.

Berger, M. J. and J. H. Hubbell. 1987b. NIST X-ray and Gamma-ray Attenuation Coefficients and Cross Sections Database, NIST Standard Reference Database 8. National Institute of Standards and Technology, Gaithersburg, Md.

Berger, M. J., et al. 1999. XCOM: Photon Cross Section Database (version 1.2), National Institute of Standards and Technology, Gaithersburg, Md. January 27, 2003, http://physics.nist.gov/xcom.

Coplen, T. B. 2001. “Atomic Weights of the Elements 1999.” Pure Appl. Chem. 73(4), 667.

Coursey, J. S., D. J. Schwab, and R. A. Dragoset. 2001. Atomic Weights and Isotopic Compositions (version 2.3.1), National Institute of Standards and Technology, Gaithersburg, MD. January 31, 2003, http://physics.nist.gov/Comp.

Eckerman, K. F., et al. 1994. “Availability of nuclear decay data in electronic form, including beta spectra not previously published.” Health Phys. 67(4), 338.

Endo, A., T. Tamura, and Y. Yamaguchi. 1999. Compilation of Nuclear Decay Data Used for Dose Calculation Revised Data for Radionuclides Not Listed in ICRP Publication 38, JAERI-Data/Code 99-035.

Endo, A., and Y. Yamaguchi. 2001. Compilation of Nuclear Decay Data Used for Dose Calculation Revised Data for Radionuclides Listed in ICRP Publication 38, JAERI-Data/Code 2001-004.

Environmental Protection Agency (EPA). 1992. Manual of Protective Action Guides and Protective Actions for Nuclear Incidents. EPA-400R-92-001, U.S. Environmental Protection Agency, Washington, DC. 
Environmental Protection Agency (EPA). 1993. External Exposure to Radionuclides in Air, Water, and Soil. Federal Guidance Report 12, U.S. Environmental Protection Agency, Washington, DC.

Environmental Protection Agency (EPA).1999. Cancer Risk Coefficients for Environmental Exposure to Radionuclides. Federal Guidance Report No. 13. EPA 402-R-99-001, U.S. Environmental Protection Agency, Washington, DC.

Environmental Protection Agency (EPA).2000. Federal Guidance Report 13: Cancer Risk Coefficients for Environmental Exposure to Radionuclides CD Supplement. EPA 402-C-99-001, U.S. Environmental Protection Agency, Washington, DC.

Howerton, R. J. 1986a. Calculated Neutron KERMA Factors Based on the LLNL ENDL Data Files. Vol. 27, UCRL-50400, Lawrence Livermore National Laboratory, Livermore, CA.

Howerton, R. J. 1986b. Calculated Photon KERMA Factors Based on the LLNL ENDL Data Files. Vol. 29, UCRL-50400, Lawrence Livermore National Laboratory, Livermore, CA.

Hubbell, J. H., and S. M. Seltzer. 1995. Tables of X-Ray Mass Attenuation Coefficients and Mass Energy-Absorption Coefficients $1 \mathrm{keV}$ to $20 \mathrm{MeV}$ for Elements $Z=1$ to 92 and 48 Additional Substances of Dosimetric Interest. NISTIR 5632; National Institute of Standards and Technology, Gaithersburg, MD.

Hubbell, J. H., and S. M. Seltzer. 1997. Tables of X-Ray Mass Attenuation Coefficients and Mass Energy-Absorption Coefficients (version 1.03). National Institute of Standards and Technology, Gaithersburg, MD. January 27, 2003, http://physics.nist.gov/xaamdi.

Idaho State University (ISU). 2003, Radioactivity in Nature, Information Network, Idaho State University Health Physics Program. 2003, http://www.physics.isu.edu/radinf/natural.htm

International Commission on Radiological Protection (ICRP). 1978. Limits for Intakes of Radionuclides by Workers. ICRP Publication 30. Annals of the ICRP Vol. 2. International Commission on Radiological Protection, Pergamon Press, New York.

International Commission on Radiological Protection (ICRP). 1983. Radionuclide Transformations: Energy and Intensity of Emissions. ICRP Publication 38. Annals of the ICRP 16:2-3. International Commission on Radiological Protection, Pergamon Press, New York.

International Commission on Radiological Protection (ICRP). 1994. Dose Coefficients for Intakes of Radionuclides by Workers. ICRP Publication 68. Annals of the ICRP 24(4). International Commission on Radiological Protection, Pergamon Press, New York.

International Commission on Radiological Protection (ICRP). 1996a. Age-dependent Doses to the Members of the Public from Intake of Radionuclides: Part 5 Compilation of Ingestion and Inhalation Coefficients. ICRP Publication 72. International Commission on Radiological Protection, Pergamon Press, New York. 
International Commission on Radiological Protection (ICRP). 1996b. Conversion Coefficients for Use in Radiological Protection Against External Radiation. ICRP Publication 74. International Commission on Radiological Protection, Pergamon Press, New York.

International Commission on Radiological Protection (ICRP). 2001. The ICRP Database of Dose Coefficients: Workers and Members of the Public. CD 1 Ver. 2.01. International Commission on Radiological Protection, Elsevier Science, New York.

Lide, D. R., editor-in-chief. 1997. CRC Handbook of Chemistry and Physics. $77^{\text {th }}$ ed. CRC Press, Inc., Boca Raton, Fla.

National Council on Radiation Protection and Measurements (NCRP). 1988. Exposure of the Population in the United States and Canada from Natural Background Radiation. NCRP 94, National Council on Radiation Protection and Measurements, Washington, DC.

Nuclear Regulatory Commission (NRC). 1996. Response Technical Manual -96 (RTM-96). Vol. 1, Rev. 4, NUREG/BR-0150, U.S. Nuclear Regulatory Commission, Washington, DC.

Rosman, K.J.R. and P.D.P. Taylor. 1998. "Isotopic Compositions of the Elements 1997.” J. Phys. Chem. Ref. Data. 27(6), 1275.

Schneider, S., et al., 2001. Systematic Radiological Assessment of Exemptions for Source and Byproduct Materials. NUREG-1717, U.S. Nuclear Regulatory Commission, Washington, DC. 


\section{INTERNAL DISTRIBUTION}

1-4. K. F. Eckerman

5. K. S. Gant

6. D. M. Hetrick

7. R. W. Leggett

8. D. A. McLaughlin

9. R. W. Rodriguez
10. P. A. Scofield

11-15. A. L. Sjoreen

16. Central Research Library

17. ORNL Laboratory Records - RC

18-19. ORNL Laboratory Records - OSTI

\section{EXTERNAL DISTRIBUTION}

20. L. Bertelli, Los Alamos National Laboratory, MS E546, Los Alamos, NM 87545

21. C. Bloom, 7 Dwight Rd., Nottingham, NH 03290

22. E. M. Brackett, 64 Sutton Dr., Vernon, CT 06066

23. Harriet Karagannis, U.S. Nuclear Regulatory Commission, MS 9 F31, 11545 Rockville Pike, Rockville, MD 20852-2738

24. C. B. Nelson. RR1 Box 4140, Sedgwick, ME 04676-0724

25. N. S. Nelson, USEPA-6608J, 1200 Pennsylvania Avenue, N.W., Washington, DC 20460

26. S. Sherbini, U. S. Nuclear Regulatory Commission, MS 8 F5, 11545 Rockville Pike, Rockville, MD 20852-2738 